\title{
An Exploratory Factor Analysis and Reliability Analysis of the Student Online Learning Readiness (SOLR) Instrument
}

\author{
Taeho Yu \\ University of Virginia \\ Jennifer C. Richardson \\ Purdue University
}

\begin{abstract}
The purpose of this study was to develop an effective instrument to measure student readiness in online learning with reliable predictors of online learning success factors such as learning outcomes and learner satisfaction. The validity and reliability of the Student Online Learning Readiness (SOLR) instrument were tested using exploratory factor analysis (EFA) and reliability analysis. Twenty items from three competencies-social competencies, communication competencies, and technical competencies-were designated for the initial instrument based on the Student Online Learning Readiness (SOLR) Model as a new conceptual model. An exploratory factor analysis (EFA) revealed that four factor-structures of the instrument of student readiness in online learning explained $66.69 \%$ of the variance in the pattern of relationships among the items. All four factors had high reliabilities (all at or above Cronbach's $\alpha>$.823). Twenty items remained in the final questionnaire after deleting two items which cross-loaded on multiple factors (social competencies with classmates: five items; social competencies with instructor: five items; communication competencies: four items; and technical competencies: six items). The four-factor structure of the Student Online Learning Readiness (SOLR) instrument has been confirmed through this study. Educators can use the Student Online Learning Readiness (SOLR) instrument in order to gain a better understanding of the level of freshmen college students' online learning readiness by measuring their social, communication, and technical competencies. In addition, this study examined two factors of social integration in Tinto's Student Integration Model (SIM) and has introduced the Student Online Learning Readiness (SOLR) conceptual model with the purpose of extending Tinto's social integration model to online learning environments.
\end{abstract}




\section{Introduction}

Online learning has become a large part of higher education (Anderson, 2014; Duck \& Parente, 2014; Kim, 2011). As of fall 2012, over 7.1 million U.S. college and university students had taken at least one online course (Allen \& Seaman, 2014); more than 71\% of US colleges and universities offered online courses (Allen \& Seaman, 2013); and one-third of higher education students were enrolled in at least one online course during the calendar year (Allen \& Seaman, 2014). According to the U.S. Department of Education's Distance Learning Report (Bakia, Shear, Toyama, \& Lasserter, 2012), the benefits of online learning are: a) to broaden access to educational resources, b) to personalize learning, c) to provide flexibility in time and location for students, and d) to reduce school-based facilities' costs. However, the benefits of online learning also bring some challenges into the field of education.

First, retention rates in online learning courses are $10 \%$ to $25 \%$ less than those in traditional face-to-face formats in higher education (Ali \& Leeds, 2009; Angelina, Williams, \& Natvig, 2007; Holder, 2007; Lee \& Choi, 2011; Poelhuber, Chomienne, \& Karsenti, 2008). Second, students who take online courses for the first time tend to feel lonely and socially isolated not only because they are new to the online learning environment but also because they are not familiar with online learning communities (Cho, Shen, \& Laffey, 2010; McInnerney \& Roberts, 2004). This feeling of social isolation has a significant relationship with distance student attrition (Ali \& Leeds, 2009; Link \& Scholtz, 2000; Reio \& Crim, 2006). Third, online learning requires learners to assume a greater responsibility for their studies and requires additional skills or competencies (Zawacki-Richter, 2004). For these reasons, it is important to offer distance learners additional forms of support in order to ensure successful online learning experiences (Watulak, 2012; Zawacki-Richter, 2004). In this manner, it becomes possible to improve student retention rates in online learning in higher education (Ali \& Leeds, 2009; Atchley, Wingenbach, \& Akers, 2012; Ludwig-Hardman \& Dunlap, 2003; Moore \& Kearsley, 2005).

Moreover, distance learners are more likely to have a lower sense of belonging than students in face-to-face formats (Ma \& Yuen, 2010). According to Goodenow (1993), the concept of a "sense of belonging" at school refers to "the extent to which students feel personally accepted, respected, included, and supported by others in the school social environment” (p. 80), and the positive relationships including a sense of belonging, student motivation, and academic achievement were verified by a series of previous research (Battistich, Solomon, Watson, \& Schaps, 1997; Flook, Repetti, \& Ullman, 2005; Furrer \& Skinner, 2003; Osterman, 2000; Tinto, 1975; Tinto, 1988; Tinto, 1993; Tinto, 1998). In line with the significance of a sense of belonging in an academic field, Tinto (1998) emphasized the positive effect of student-faculty interactions and student-student interactions on students' senses of belonging. In addition, technological elements, such as computer skills or Internet connections, are important success factors for online learning, including learning outcomes and learner satisfaction (Ben-Jacob, 2011; Herrera \& Mendoza, 2011; Watulak, 2012). For this reason, it is necessary to provide support for distance learners in order to enhance their social competencies with instructors and classmates as well as their communication competencies and technical competencies so that they can have a better learning experience.

One preemptive way to accomplish this is by assisting students to more accurately gauge their readiness for online learning before they start a program. Distance learners should be provided with an opportunity to develop their competencies or readiness skills to better avoid a problematic situation involving non-content related learning challenges that could prevent success in online learning. For this reason, it is essential to both measure and enhance the learner's readiness for online learning before they take an online course. However, many educators in higher education do not know how to measure their learners' social, communication, and technical competencies which are required to succeed in such environments (Yu, 2014). Moreover, although a number of universities develop and implement their own online learning readiness surveys, these surveys-as discussed previously-tend to focus more on computer or Internet skills, technology accessibility, and general learner characteristics such as attitudes 
toward online education or personal learning preferences (Bernard, Brauer, Abrami, \& Surkes, 2004; Kerr, Rynearson, \& Kerr, 2006; Watkins, Leigh, \& Triner, 2004).

For these reasons, the purpose of this study is to develop a more specified instrument designed to measure student readiness in online learning through a focus on social, communication, and technical competencies. The development of a new instrument to measure distance learners' online learning readiness is significant for the future of the field of online learning and will provide useful and practical suggestions for administrators and educators in higher education as well as for the distance learners themselves. First, by using the existing literature related to a student's online learning readiness as a guide, a new instrument will be developed to measure the social, communication, and technical competencies of the varied learners within online learning environments. Second, the reliability and validity evidence of the developed instrument employed to measure social, communication, and technical competencies will be evaluated. The specific research questions addressed in this study are:

1. Which set of items should appropriately be included in the final instruments based on analyses of psychometric properties of the developed instrument that measures social competencies, communication competencies, and technical competencies?

2. What is the reliability and validity evidence of the developed instrument to measure social competencies, communication competencies, and technical competencies?

\section{Literature Review}

Previous research has supported the importance of measuring student readiness in online learning prior to students taking an online course (McVay, 2000, 2001; Parnell \& Carraher, 2002; Smith, 2005; Watkins, Leigh, \& Triner, 2004), as well as the significant impact of student readiness on student academic achievement within online learning environments (Bernard et al., 2004; Kerr et al., 2006). In addition, it is necessary to provide adequate social and academic support services in order to enhance students' senses of belonging in online learning both for increased meaningful learning experiences and higher retention rates (Ali \& Leeds, 2009; Atchley, Wingenbach, \& Akers, 2012; Ludwig-Hardman \& Dunlap, 2003).

With respect to learner competencies, the terms "competency" and "competence" have been used as substitutes for one another in many studies. However, these two terms are slightly different from each other. The International Board of Standards for Training, Performance and Instruction (IBSTPI) defined competency as "a knowledge, skill, or attitude that enables one to effectively perform the activities of a given occupation or function the standards expected in employment" (Spector, 2001, p. 180). On the other hand, according to Kerka (1998), "competence is individualized, emphasizes outcomes (what individuals know and can do), and allows flexible pathways for achieving the outcomes-making as clear as possible what is to be achieved and the standards for measuring achievement" (p. 2). With the understanding of these terms, as so defined, the word "competency" will be used for the purpose of this study.

Competencies are an individual's perception of his or her ability or capability. For this study social competencies are defined as skills, competencies, and the feeling of control essential for managing social situations and building and maintaining relationships (Myllylä \& Torp, 2010). Communication competencies are defined as "the ability to demonstrate knowledge of the socially appropriate communicative behavior in a given situation" (p. 24). Technical competencies are defined as "selfefficacy in technology” (Heo, 2011, p. 61).

The effect of learners' competencies on their academic achievement has been studied in the field of online education. First, the importance of social competencies for distance learners' academic 
achievement has been supported (Chen et al., 2010; Parker et al., 2006; Williams, 2003). Cho and Jonassen (2009) found that there is a significant correlation between success in online learning environments and the student's social competencies in interacting with his or her instructor and peers in online courses. Second, a sizeable number of studies have proposed that interpersonal and communication competencies are the most influential predictors of academic achievement (Betermieux \& Heuel, 2009; Dabbagh, 2007; Dabbagh \& Bannan-Ritland, 2005; Volery \& Lord, 2000; Williams, 2003). Third, technical competencies are considered to be a necessary component for successful learning experiences in online education (Osika \& Sharp, 2002; Selim, 2007; Watulak, 2012; Whale, 2006). Moreover, in terms of the influence of technical competencies on online education, Herrera and Mendoza (2011) proposed that technical competencies are a significant predictor for learning outcomes in online learning, which has been confirmed by Cho (2012), Ben-Jacob (2011), and Selim (2007).

However, although several studies have introduced various measures for technical competencies (Osika \& Sharp, 2002; Saud et al., 2010; Selim, 2007; Soong et al., 2001; Wozney, Venkatesh, \& Abrami, 2006), it is necessary to update these measurements to more adequately and appropriately qualify and quantify the current online learning environment. Most existing student readiness instruments have included basic computer skill questions (Bernard, Brauer, Abrami, \& Surkes, 2004; Dray \& Miszkiewicz, 2007; Mattice \& Dixon, 1999; McVay, 2001; Parnell \& Carraher, 2003; Watkins et al., 2004), learner characteristics (Bernard, Brauer, Abrami, \& Surkes, 2004; Dray \& Miszkiewicz, 2007; Kerr, Rynearson, \& Kerr, 2006; Mattice \& Dixon, 1999; McVay, 2001; Parnell \& Carraher, 2003; Watkins et al., 2004), and demographic questions (Dray \& Miszkiewicz, 2007; Mattice \& Dixon, 1999). For instance, Bernard and his colleagues developed an online survey with 38 items to measure four categories of learner readiness in online education: a) readiness of online skills; b) readiness of self-management of learning and learning initiative; c) readiness of beliefs about DE/online learning; and d) desire for interaction with an instructor and/or other students (Bernard et al., 2004, p. 33). Osika and Sharp (2002) and Saud et al. (2010) proposed measuring technical competencies that would be considered outdated at this time, such as formatting a disk, copying a file from one disk drive to another, sending and receiving e-mail, and properly starting and shutting down a personal computer.

In summary, it has been revealed that the prevailing student readiness instruments employed in today's online learning are focused on asking computer or Internet related questions in order to measure students' technological abilities to access online courses via computers and/or Learning Management Systems (LMS). However, each student's access to an online course does not always guarantee that student's success. In addition, most existing readiness instruments do not include social readiness although it is a significant factor in online learning. Therefore, other aspects - such as social, communication, and technical competencies-must also be considered as essential components of the student readiness instruments in online learning.

\section{Theoretical Framework}

The theoretical framework for this study stems from the work of Tinto (1975) and his Student Integration Model (SIM), which determines factors that can increase student retention. Although Tinto's work was based on traditional face-to-face formats, the principles remain the same for learners in distance classes. He asserted that those students who are not sufficiently integrated into the social and academic aspects of a college or university tend to "dropout" or remove themselves from their purported plans of study. In other words, he stressed the importance of students' social and academic integration into university life as an element necessary to decrease dropout rates (Tinto, 1975; Tinto, 1998; Tinto, 2000; Tinto, 2005; Tinto, 2006; Tinto, 2008). In the SIM, which is the most influential model of student retention in higher education (McCubbin, 2003), Tinto (1975) elucidated which aspects and processes were related to the individual student's decision to leave the college or university and proposed five internal factors as significant predictors of student retention: a) academic integration; b) social 
integration; c) goal commitment; d) institutional commitment; and e) the learning community as shown in Figure 1 (p. 95).

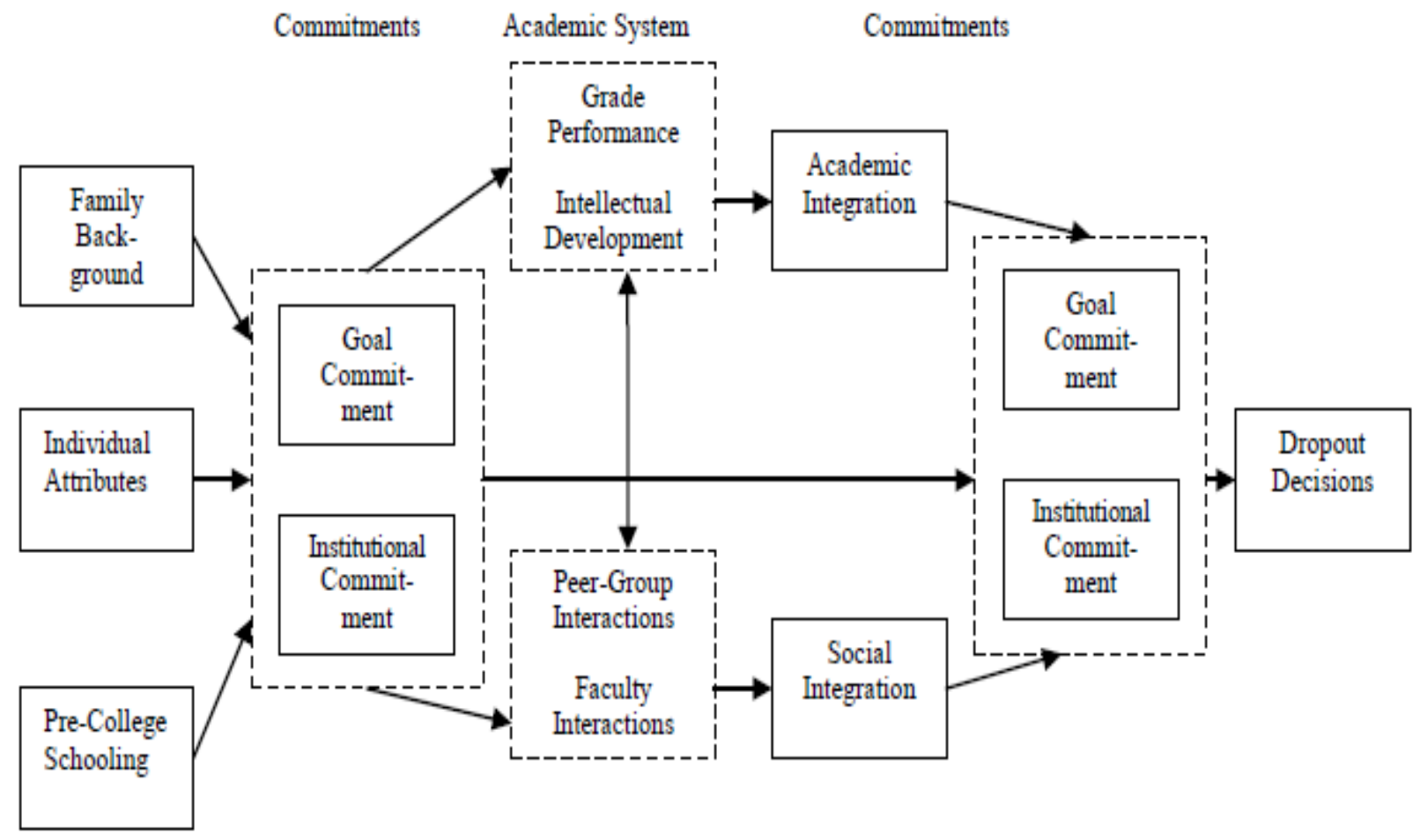

Social System

Figure 1. Tinto’s Student Integration Model (SIM)

Tinto (1975) considered social integration and academic integration as the most significant factors for student retention among the five internal factors. He asserted that social integration consists of the student's quality of relationship with the course instructor and classmates, whereas academic integration relates to the student's academic performance and their level of intellectual development (Tinto, 1975, Tinto, 1998; Tinto, 2000; Tinto, 2005; Tinto, 2006). In addition, Tinto (1975) claimed that the level of social and academic integration have positive relationships with students' goal commitments and institutional commitments. In other words, students who achieve higher levels of social and academic integration tend to have strong goal commitments and institutional commitments and, as a result, tend not to drop out. Moreover, in the SIM, social integration plays a key role (Tinto, 1975; Tinto, 1998; Tinto, 2000; Tinto, 2005; Tinto, 2006; Tinto, 2008). Tinto (1975) asserted that the student's social integration, such as the student's interaction with course instructors and classmates, may enhance academic integration, help students to form learning communities, and resultantly increase student retention. Based on the SIM, Tinto also proposed three supports which have a positive effect on student retention - social support, academic support, and financial support (Tinto, 1975; Tinto, 1998; Tinto, 2000; Tinto, 2005; Tinto, 2008), and he proposed five conditions for student retention (Tinto, 2006).

While Tinto's model includes elements outside of the scope of this study, such as financial support, it is suitable as a theoretical framework and includes the major elements being studied. Furthermore, Tinto's SIM suggests that there is a significance in social integration, such as students' 
interactions with instructors and classmates. In addition, communication competencies are an important element for enhancing student interaction with instructors and classmates (Dabbagh, 2007; Dray \& Miszkiewicz, 2007). Last but not least, technical competencies are a substantial component for distance learners as it is the mediating element by which the others are implemented. Therefore, this study proposes the Student Online Learning Readiness (SOLR) Model as a new conceptual model for student retention in online learning that was inspired by Tinto’s SIM as shown in Figure 2.

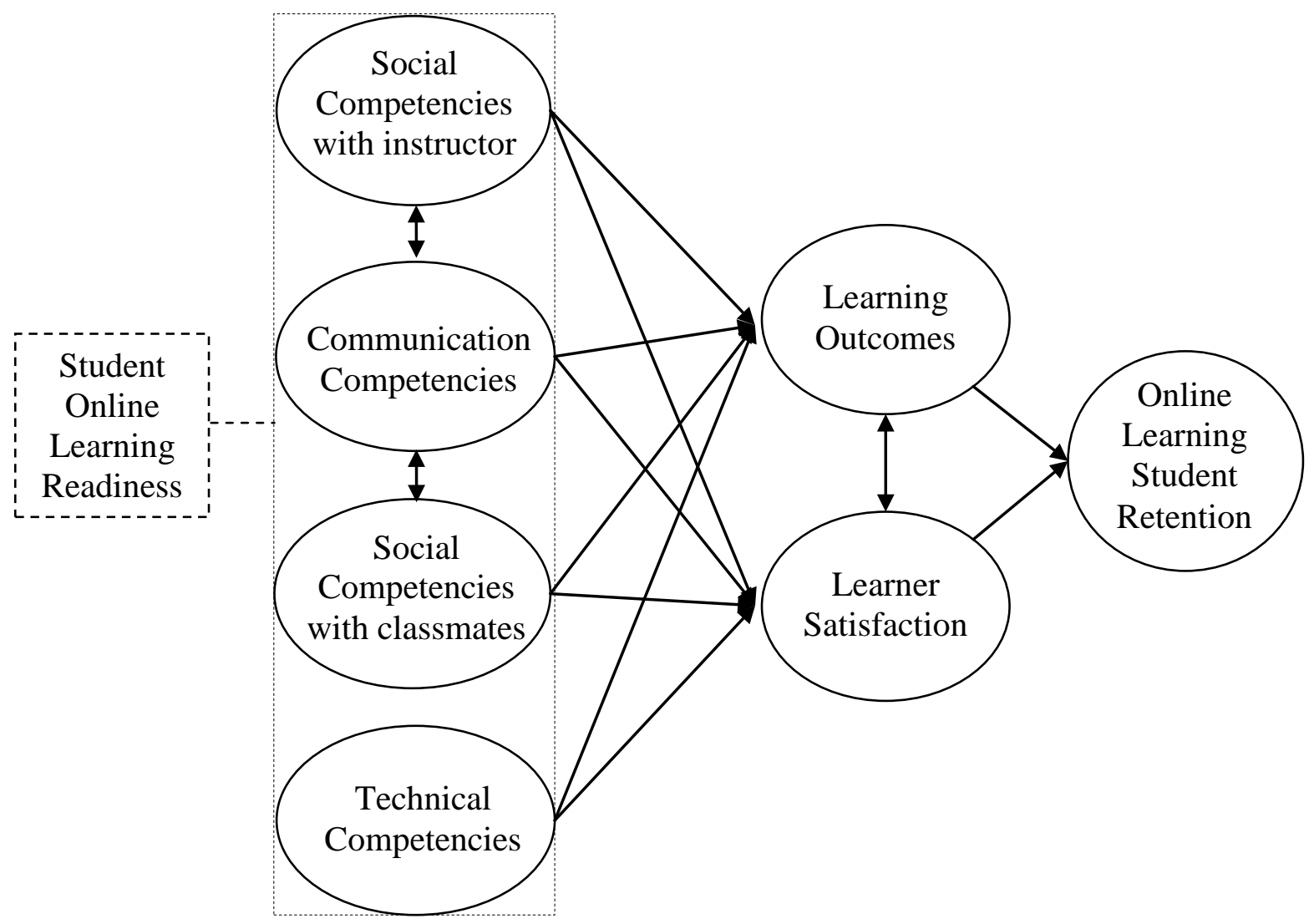

Figure 2. Student Online Learning Readiness (SOLR) Model

The Student Online Learning Readiness (SOLR) Model consists of four components believed necessary to measure student readiness for online learning, such as social competencies with the instructor, communication competencies, social competencies with classmates, and technical competencies. The positive relationships of each component with learning outcomes or learner satisfaction in an online learning environment have been verified in previous research (e.g. for social competencies with the instructor see Shen, Cho, Tsai, \& Marra, 2013; for communication competencies see Betermieux \& Heuel 2009; for social competencies with classmates see Shen et al., 2013; and for technical competencies see Cho, 2012; Herrera \& Mendoza, 2011). In addition, the influence of learning outcomes and learner satisfaction on student retention rates in online learning has been supported (Carey, 2011; Lee \& Choi, 2013). That is, student readiness in online learning as measured by social competencies with the instructor, communication competencies, social competencies with classmates, and technical competencies play a significant role in the enhancement of student retention in online learning in the Student Online Learning Readiness (SOLR) Model. 


\section{Methods}

\section{Research Context}

A survey was created and administered using the Purdue Qualtrics system, and the survey links were distributed through Blackboard Learn in the Spring 2014 semester. Twelve online courses at a large Midwestern university were selected across program areas, including social science, engineering, agriculture, and others, in order to reduce possible bias in competencies levels among learners in a particular program. All online courses selected for this study had the following features: a) students were undergraduates; b) the courses were only offered online; c) class assignments and exams were implemented in Blackboard Learn; and d) all instruction was conducted using Blackboard Learn. The total enrollment of the largest class and the smallest class were 200 and 2 respectively. The highest response rate was $85 \%$, whereas the lowest response rate was $20 \%$. Data were checked for duplicate responses by comparing participating students' names and email addresses, and duplicate responses were removed. The average response rate was $51.54 \%$.

\section{Participants}

There were 331 students who participated in this study and their majors included psychology, industrial engineering, animal science, computer science, political science, management, and communications. In terms of the academic levels, $47.1 \%$ of participating students were seniors, $20.5 \%$ were juniors, $17.8 \%$ were sophomores, and $14.5 \%$ were freshmen. One hundred and eighty seven female students (56.5\%) and 144 male students (43.5\%) participated in this study. The majority of the participating students in this study (96\%) reported being between 18-23 years old. With respect to online learning experiences, $35.3 \%$ of the participating students answered that the present course was their first online course and $29.0 \%$ of students answered that they had taken at least two online courses, including the present course. Therefore, from the table statistics, one may conclude that at least two thirds of the participating students had participated in one or two online courses, whereas one third of participating students (35.6\%) had taken more than two online courses.

\section{Survey Instrument}

From the review of literature, 22 self-reported items were selected for this study. The questionnaire used in the current study consisted of five items for the measurement of social competencies with the instructor in online learning (Shen et al., 2013), five items for the measurement of social competencies with classmates in online learning (Shen et al., 2013), six items for the measurement of communication competencies in online learning (Dray et al., 2011; McVay 2001), and six items for the measurement of technical competencies in online learning (Wozney et al., 2006). A five-point Likert scale (1=Disagree, $2=$ Tend to disagree, $3=$ Neutral, $4=$ Tend to agree, $5=$ Agree) was used for each item.

Social competencies measurement in online learning. The 10-item self-reported measurement of social competencies scale from Shen et al. (2013) was used to measure learners' perceived social competencies in this study. Originally, the Shen et al. (2013) online learning self-efficacy scale consisted of 30 items with five categories: a) self-efficacy to complete an online course (8 items); b) self-efficacy to interact socially with classmates (5 items); c) self-efficacy to handle tools in a Course Management System (CMS) (6 items); d) self-efficacy to interact with instructors in an online course (5 items); and e) self-efficacy to interact with classmates for academic purposes (6 items). However, five items of selfefficacy for interacting with instructors in an online course and five items of self-efficacy for interacting socially with classmates directly related to measuring social competencies in online learning environment were selected for this study. These items were directly related to social competencies to enhance the distance learner's sense of belonging in online courses and had a positive relationship with academic 
achievement. In the original Shen et al. (2013) online learning self-efficacy scale, Cronbach's alpha for internal consistency for each subscale was 0.93 , 0.92, 0.93, 0.94, 0.93 respectively. Permission to use the questionnaires from Shen et. al.’s (2013) study was obtained for use in this study.

Communication competencies measurement in online learning. To measure communication competencies in online learning, four items from the online learning readiness survey (OLRS) of Dray et al. (2011), and two items from McVay's (2001) student self-evaluation inventory, were adapted for this study. Dray et al.'s (2011) Online Learning Readiness Survey (OLRS) consists of 14 items which were derived from the literature related to the distant learner's readiness for online learning (see Bernard et al., 2004; Mattice \& Dixon, 1999; and McVay, 2001). According to Dray and Miszkiewicz (2007), three learner characteristics were each considered as a component for the online learning readiness survey (OLRS), including psychological characteristics (e.g. motivation, attitude, and confidence), learning style (group work, independence, and communication), and situational factors (commuting issues, schedule conflicts, and access). Within these three learner characteristics, four items were designed to measure a distance learner's communication competencies; for the purpose of this study, these four items were selected from the Dray et al. (2011) online learning readiness survey (OLRS). Cronbach's alpha for internal consistency among the six items of self-efficacy subscale was 0.77. Permission to use the questionnaires from both Dray's and McVay's studies was obtained for use in this study.

Technical competencies measurement in online learning. Six items were selected from the instrument by Wozney et al. (2006) and modified to measure distance learners' technical competencies; the original instrument was developed to measure teachers' technical competencies. The original instrument consisted of 33 items related to teachers' attitudes and beliefs toward using computer technology in their classroom, such as "the use of computer technology in the classroom motivates students to get more involved in learning activities” (p. 202). Wozney et al.'s (2006) original instrument consisted of four sections: a) professional views on computer technology; b) background, teaching style, and resources available; c) experience with computer technologies; and d) process of integration. Survey items labeled TC1, 3, 4, and 5 were selected from the section of teacher's process of integration in Wozney et al. (2006). This section was designed to ask teachers about their perceptions of the process of integrating computer technology in teaching activities. Survey items labeled TC2 and TC6 were selected from the section on experience with computer technologies and the section on professional views of computer technology in Wozney et al. (2006), respectively. Because these original items were designed for teachers' technical competencies assessments, they were modified to measure learner's technical competencies in an online learning environment. In terms of internal consistency for the original scale, Cohen’s Kappa was 0.86 for Wozney et al. (2006).

\section{Data Analyses}

The main purpose of this research phase was to examine the appropriateness of the items and the internal structure of the constructs that the instrument measures. For these reasons, an exploratory factor analysis was first conducted to evaluate the factor structure of the scale. Second, a reliability analysis on pilot items was executed to test the reliability of the preliminary questionnaire set.

Statistical evidence of validity with Exploratory Factor Analysis (EFA). Exploratory factor analysis (EFA) is a statistical method that increases the reliability of the scale by identifying inappropriate items that can then be removed. It also identifies the dimensionality of constructs by examining relations between items and factors when the information of the dimensionality is limited (Netemeyer, Bearden, \& Sharma, 2003). For this reason, EFA is performed in the early stages of developing a new or revised instrument (Wetzel, 2011). Before performing EFA, measurement appropriateness for the 22 survey items was evaluated through use of descriptive statistics. To accomplish this, both the mean of all responses and the standard deviations (SD) per item were calculated. If the mean of an item was found to be close to 
either 1 or 5, eliminating it as inappropriate should be considered because it may decrease the standard of correlation among the rest of the items (Kim, 2011). Following this step, the normality in distribution was tested by examining skewedness and kurtosis before conducting an exploratory factor analysis. Since the normality of the distribution was confirmed, the exploratory factor analysis was conducted through use of the Statistical Package for the Social Sciences (SPSS, version 22).

In this study, four factors - social competencies with instructor, social competencies with classmates, communication competencies, and technical competencies-were used to determine the structural pattern of the preliminary question set along with a scree plot and eigenvalue (Thompson, 2004). Scree tests, which were introduced by Cattell (1966), plot eigenvalues against the number of factors in order to best determine where a significant drop occurs within factor numbers (Netemeyer, Bearden, \& Sharma, 2003). The factor solution was determined based on the number of eigenvalues greater than one (Kaiser, 1960). Following recommendations by Floyd and Widaman (1995), .30 was used as a factor loading criterion in EFA. Kass \& Tinley (1979) recommended five to ten participants per item and Comrey \& Lee (1992) claimed that a sample size of 200 is fair and 300 is good. In addition, Boomsma (1982) recommended a minimum sample size of 200 to achieve reliable results when conducting a factor analysis.

The exploratory factor analysis process began with an initial analysis run to obtain eigenvalues for each factor in the data. Next, the Kaiser-Meyer-Olkin (KMO) Measure of Sampling Adequacy (KMO) test and Bartlett's Test of Sphericity were executed to determine construct validity and to confirm that the data collected for an exploratory factor analysis were appropriate. The KMO test was used to verify the sampling adequacy for the analysis, and Bartlett's Test of Sphericity was used to determine if correlations between items were sufficiently large for EFA. Bartlett's Test of Sphericity should reach a statistical significance of less than .05 in order to conduct an EFA. If the results of the initial EFA show items which are loading on the wrong factors or cross-loading on multiple factors, those items are deleted in order and the EFA re-performed until a simple solution is achieved.

Reliability analysis. The reliability of an instrument or questionnaire is concerned with the consistency, stability, and dependability of the scores (McMillan, 2007). For this reason, the internal consistency was tested using Cronbach's alpha for each competency in SPSS. If the alpha value is higher than 0.9, the internal consistency is excellent, and if it is at least higher than 0.7, the internal consistency is acceptable (Blunch, 2008). Excellent internal consistency means that the survey items tend to pull together. In other words, a participant who answers a survey item positively is more likely to answer other items in the survey positively (Blunch, 2008).

\section{Results}

\section{Descriptive Statistics}

Table 1 (next page) shows the descriptive statistics, including the means, standard deviations, minimums, and maximums of the four proposed factors of the Student Online Learning Readiness (SOLR) instrument. It revealed that participating students had a high level of communication competencies $(M=4.319)$, social competencies with the instructor $(M=4.272)$, and technical competencies $(M=4.249)$, whereas they felt a relatively low level of social competencies with classmates $(M=3.707)$. 
Table 1 Descriptive statistics of each element of the Student Online Learning Readiness (SOLR) instrument

\begin{tabular}{llllllll}
\hline & Mean & Std. Deviation & Skewedness & Kurtosis & Min & Max & N \\
\hline $\begin{array}{l}\text { Technical } \\
\text { competencies }\end{array}$ & 4.249 & .846 & -.910 & .179 & 1 & 5 & 331 \\
$\begin{array}{l}\text { Social competencies } \\
\text { with classmates }\end{array}$ & 3.707 & 1.059 & -.580 & -.054 & 1 & 5 & 331 \\
$\begin{array}{l}\text { Social competencies } \\
\text { w/ the instructor }\end{array}$ & 4.272 & .873 & -.974 & .633 & 1 & 5 & 331 \\
$\begin{array}{l}\text { Communication } \\
\text { competencies }\end{array}$ & 4.319 & .807 & & & & & \\
Total & 4.128 & .7055 & -.945 & .229 & 1 & 5 & 331 \\
\hline
\end{tabular}

The minimum and maximum values were the same in all four competencies-one and five, respectively. In addition, the results supported the variables as normally distributed based on the degrees of skewedness and kurtosis because both were less than the absolute value of one. The rule of thumb was also applied to test the normal distribution of the data because the sample size was larger than 200 participants (Field, 2009). With a large sample, it is more important to visually assess the distribution shape than to test the statistical significance of skewedness and kurtosis (Field, 2009).

\section{Exploratory Factor Analysis (EFA) for Validity}

An exploratory factor analysis was conducted on the 22 items with a promax rotation using SPSS. Exploratory factor analysis is a statistical method employed to increase the reliability of the scale by identifying inappropriate items that can be removed and the dimensionality of constructs by examining the existence of relationships between items and factors when the information of the dimensionality is limited (Netemeyer, Bearden, \& Sharma, 2003). In this study, the four factors (i.e., technical competencies, social competencies with classmates, social competencies with the instructor, and communication competencies) were used to determine the pattern of the structure in the 22-item Student Online Learning Readiness (SOLR) instrument and were used to create a scree plot (Thompson, 2004).

\section{Preliminary Four-Factor Structure}

An initial analysis was run to obtain eigenvalues for each factor in the data. The Kaiser-MeyerOlkin Measure verified the sampling adequacy for the analysis, $\mathrm{KMO}=.914$ which is above Kaiser's recommended threshold of 0.6 (Kaiser, 1974). Bartlett's test of sphericity, $\chi^{2}(231)=4364.42, \mathrm{p}<.000$, indicated that correlations between items were sufficiently large for EFA. Four factors had eigenvalues greater than one, as the scree plot clearly illustrates in Figure 3 (next page). The initial 22-item structure explained $65.41 \%$ of the variance in the pattern of relationships among the items. The percentages explained by each factor were $41.075 \%$ (technical competencies), 10.212\% (social competencies with instructor), 7.205\% (communication competencies), and 6.923\% (social competencies with classmate), respectively.

Based on the results of the initial exploratory factor analysis, there were two items which loaded on two factors in the preliminary four-factor structure. Both items were initially hypothesized to load on 
the communication competencies of the initial Student Online Learning Readiness (SOLR) instrument, but they were also loading on technical competencies. The first item was "I am comfortable communicating electronically"; the factor loading on communication competencies was .331, and the cross-loading on technical competencies was .432. The second item was "I am willing to actively communicate with my classmates and instructors electronically"; the factor loading on communication competencies was .317, and the cross-loading on technical competencies was .322.

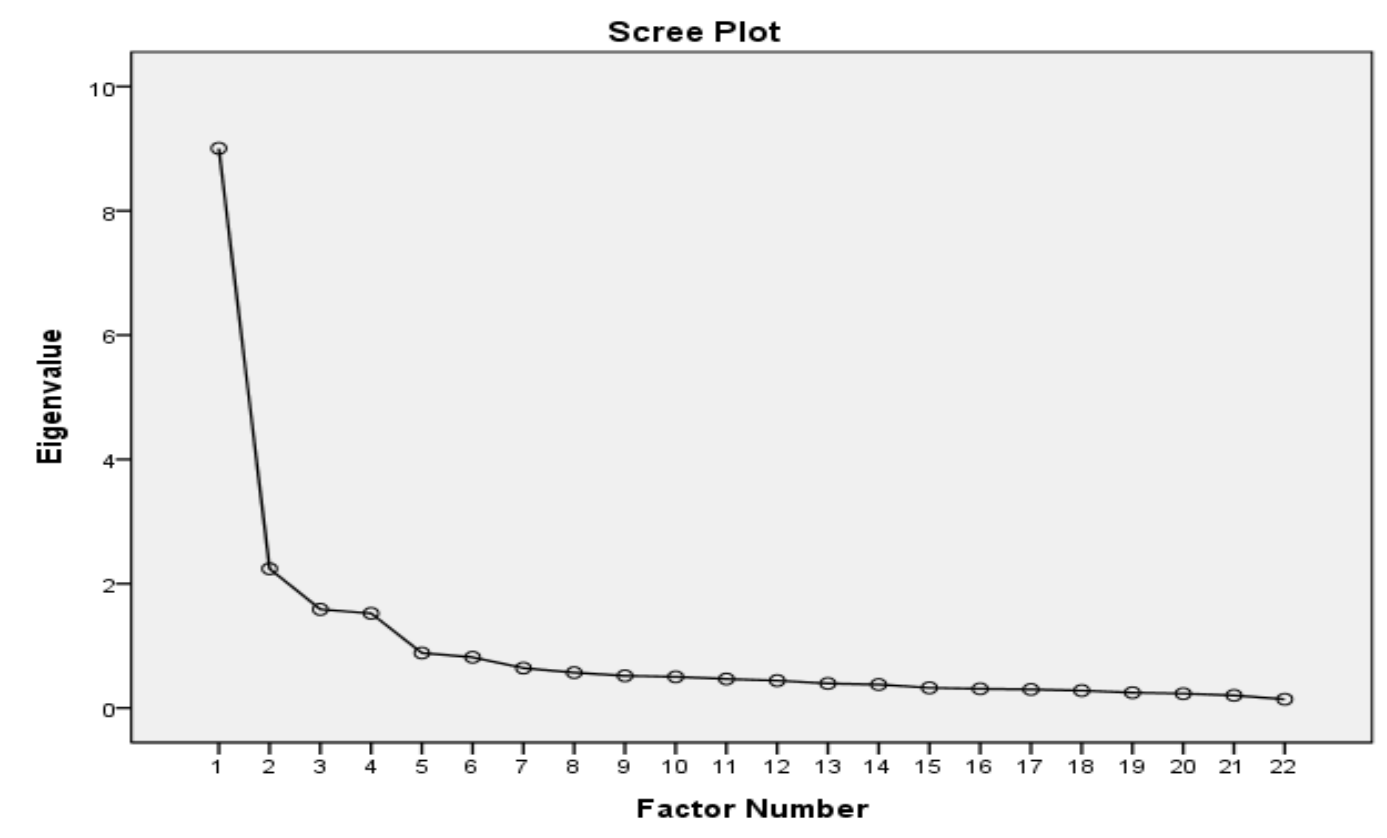

Figure 3. Scree Plot for the Student Online Learning Readiness (SOLR) Instrument

\section{Final Four-Factor Structure}

After deleting two items which cross-loaded on two factors, the final four-factor structure in this study was composed of 20 items. As is shown in Table 3 (nect page), six items for factor 1 represent technical competencies, five items for factor 2 represent social competencies with the instructor, and five items for factor 3 represent social competencies with classmates, and four items for factor 4 represent communication competencies. The first item that was deleted was "I'm comfortable communicating electronically" because it had a factor loading of .331 on communication competencies and a crossloading of .432 on technical competencies. The second item that was deleted was "I am willing to actively communicate with my classmates and instructors electronically” because the factor loading was under .32 (Tabachnick \& Fidell, 2013).

Finally, this 20 -item structure was found to explain $66.69 \%$ of the variance in the pattern of relationships among the items as shown in Table 2 (next page). The percentages explained by each factor were $40.284 \%$ (technical competencies), 11.019\% (social competencies with instructor), $7.912 \%$ (social competencies with classmate), and $7.474 \%$ (communication competencies) respectively. Moreover, three competencies (e.g. social competencies, communication competencies, and technical competencies) in this study were highly correlated to each other, as is shown in Table 3. The factor correlation between factor 1 (technical competencies) and factor 2 (social competencies with the instructor) was .612; the correlation between factor 2 and factor 3 (social competencies with classmates) was .456; the correlation 
between factor 3 and factor 4 (communication competencies) was .443; the correlation between factor 1 and factor 3 was .369; the correlation between factor 2 and factor 4 was .582; and the correlation between factor 1 and factor 4 was .550.

Table 2 Eigenvalues, Total Variances Explained for the Final Four-Factor Structure

\begin{tabular}{|c|c|c|c|c|c|c|c|}
\hline \multirow[b]{4}{*}{ Factor } & \multirow{2}{*}{\multicolumn{3}{|c|}{ Initial Eigenvalues }} & \multirow{2}{*}{\multicolumn{2}{|c|}{$\begin{array}{l}\text { Extraction } \\
\text { Squared Loadings }\end{array}$}} & \multirow[t]{2}{*}{ Sums } & \multirow{2}{*}{$\begin{array}{l}\text { of Rotation Sums of } \\
\text { Squared Loadings }^{\text {a }}\end{array}$} \\
\hline & & & & & & & \\
\hline & & $\%$ & f Cumulative & & $\% \quad$ of & & \\
\hline & Total & Variance & $\%$ & Total & Variance & Cumulative \% & Total \\
\hline 11 & 8.057 & 40.284 & 40.284 & 7.664 & 38.322 & 38.322 & 5.880 \\
\hline 2 & 2.204 & 11.019 & 51.303 & 1.788 & 8.939 & 47.262 & 5.944 \\
\hline ' 3 & 1.582 & 7.912 & 59.215 & 1.220 & 6.099 & 53.361 & 4.217 \\
\hline ] & & & & & & & \\
\hline 4 & 1. 495 & 7.474 & 66.689 & 1.118 & 5.590 & 58.951 & 5.317 \\
\hline
\end{tabular}

Table 3 Factor Correlation Matrix

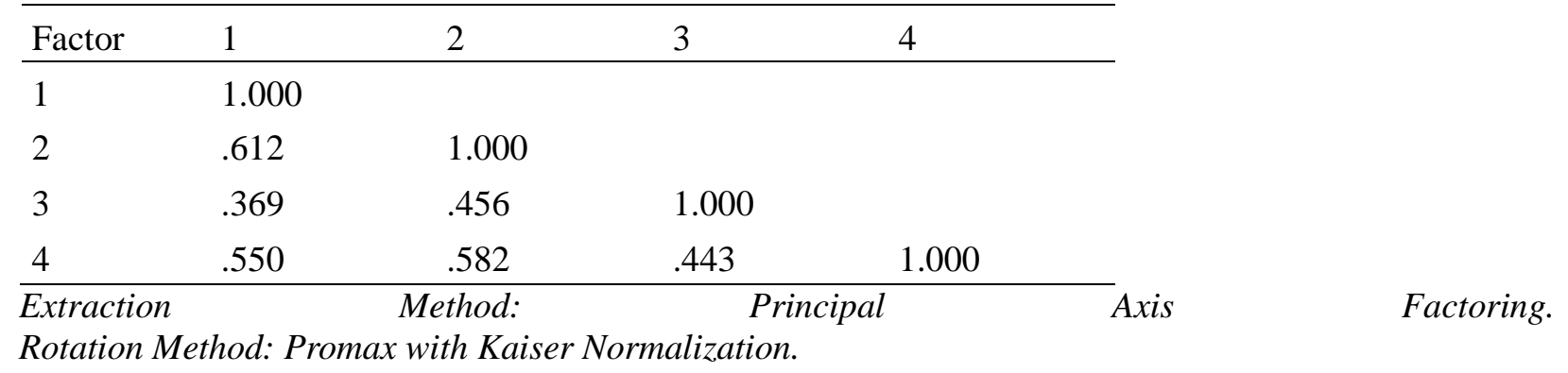

In the final four-factor structure of the Student Online Learning Readiness (SOLR) instrument, there was one item which was under .32 factor loading (i.e. I am willing to actively communicate with my classmates and instructors electronically). In fact, Tabachnick and Fidell (2013) suggested deleting those items under .32 factor loading for a better interpretation of the factor structure. These items are not considered to load significantly. However, when choosing to decide appropriately to delete an item under .32 factor loading, this study also examined the Cronbach's $\alpha$ if the item were to be deleted. Although deleting the item was associated with a decrease in $\alpha$, the item was nonetheless deleted. The original Cronbach's $\alpha$ of factor 1 (technical competencies) was .887 and if the item ("I am willing to actively communicate with my classmates and instructors electronically") is deleted, then the Cronbach's $\alpha$ of factor 1 would be decreased to .882 . However, the .005 gap on the Cronbach's $\alpha$ is so minimal it might not be considered as significant. In addition, this item is not strong and shares a potential cross-loading. For this reason, the item ("I am willing to actively communicate with my classmates and instructors electronically") was deleted in this study. 
Table 4 The Items and Final Four-Factor Structure of the Student Online Learning Readiness (SOLR) Instrument after Factor Reduction Procedures

\section{Factor}

$\begin{array}{llll}1 & 2 & 3 & 4\end{array}$

\section{Factor 1: Technical Competencies}

1. I have a sense of self confidence in using computer technologies for specific .988 tasks.

2. I am proficient in using a wide variety of computer technologies. .858

3. I feel comfortable using computers.

4. I can explain the benefits of using computer technologies in learning.

5. I am competent at integrating computer technologies into my learning .591 activities.

6. I am motivated to get more involved in learning activities when using .455 computer technologies.

\section{Factor 2: Social Competencies with instructor}

(How confident are you that you could do the following social interaction tasks with your INSTRUCTOR in the ONLINE course?)

7. Clearly ask my instructor questions.

8. Initiate discussions with the instructor.

9. Seek help from instructor when needed.

10. Timely inform the instructor when unexpected situations arise.

\section{Factor3: Social Competencies with classmates}

(How confident are you that you could do the following social interaction tasks with your CLASSMATES in the ONLINE course?)

12. Develop friendship with my classmates.

13. Pay attention to other students’ social actions. $\quad$.768

14. Apply different social interaction skills depending on situations. $\quad .755$

15. Initiate social interaction with classmates. $\quad .718$

16. Socially interact with other students with respect. $\quad .378$ 


\section{Factor 4: Communication Competencies}

17. I am comfortable expressing my opinion in writing to others. mean.

20. I give constructive and proactive feedback to others even when I disagree.

\section{Item Analysis for Reliability}

An item analysis was conducted to test the reliability of each factor of the Student Online Learning Readiness (SOLR) instrument. According to Blunch (2008), satisfactory internal consistency ranges from 0.7 to 0.9 . All four factors on this scale had a high rating for reliability. The Cronbach's $\alpha$ for technical competencies, social competencies with the instructor, communication competencies, and social competencies with classmate were .882, .874, .871, and .823, respectively (see Table 5).

Table 5 Cronbach's Alpha for Each Element of the Student Online Learning Readiness (SOLR) Instrument

\begin{tabular}{|c|c|c|c|}
\hline & $\begin{array}{l}\text { Cronbach's } \\
\text { Alpha }\end{array}$ & $\begin{array}{l}\text { Cronbach's Alpha Based on } \\
\text { Standardized Items }\end{array}$ & $\begin{array}{l}\text { Number of } \\
\text { items }\end{array}$ \\
\hline Technical competencies & .882 & .890 & 6 \\
\hline Social competencies with classmate & .823 & .825 & 5 \\
\hline Social competencies with the instructor & .874 & .875 & 5 \\
\hline Communication competencies & .871 & .872 & 4 \\
\hline
\end{tabular}

\section{Discussion}

As a result of our exploratory factor analysis (EFA), four factor-structures of the instrument of student readiness in online learning explained $66.69 \%$ of the variance in the pattern of relationships among the items. All four factors had high reliabilities (all Cronbach's $\alpha>.823$ ). Twenty items remained in the final questionnaire after deleting two item which cross-loaded on multiple factors (social competencies with classmates: 5 items; social competencies with instructor: 5 items; communication competencies: 4 items; and technical competencies: 6 items). As a result, the four-factor structure of the Student Online Learning Readiness (SOLR) instrument has been confirmed through this study.

In addition, it was confirmed that the data included this study was appropriate in order to conduct a valid exploratory factor analysis (EFA) based on the descriptive statistics analysis. The 331student sample size was large enough for the EFA because it was larger than the suggested sample size of 300 (Comrey \& Lee, 1992). Based on the results of the exploratory factor analysis, this study has successfully achieved the simple solution with four-factor structures by deleting two items which crossloaded on multiple factors. In the initial solution, both factor 2 and factor 4 can be seen to clearly represent social competencies with the instructor and social competencies with classmates, respectively. However, two items cross-loaded on both factor 1 (technical competencies) and factor 3 (communication competencies), such as "I am comfortable communication electronically" and "I am willing to actively 
communicate with my classmates and instructors electronically.” These two items were supposed to load on factor 3 (communication competencies). But, through the use of the word "electronically" it has been found that there may have been a cross-loading on both communication competencies and technical competencies. Moreover, the factor loadings of these items on factor 1 were .432 and .322, whereas .331 and .317 on factor 3. That is, these items loaded on the wrong factor. Therefore, by deleting the items we felt loaded on the wrong factor (e.g. "I am comfortable communicating electronically" and "I am willing to actively communicate with my classmates and instructors electronically"), I believe that the final solution could be better achieved in this study.

During the first phase of the instrument development process, this study examined the reliability and validity of the instrument. Based on the results of the EFA of this study, educators or administrators can use this Student Online Learning Readiness (SOLR) instrument in order to discover a better understanding of the level of freshmen college students' online learning readiness capabilities by measuring three competencies; social, communication, and technical competencies. Moreover, when students come to understand their level of online learning social readiness, the instrument may provide them with an opportunity to enhance their readiness prior to taking their first online course. However, further research is necessary to examine the relationships which exist among the latent and manifest variables by conducting a confirmatory factor analysis (CFA) (Schreiber, Stage, King, Nora, \& Barlow, 2006).

The SOLR can provide student profiles for administrators or institutions which are looking to create student support structures for the success of distance learners in courses or programs. While these social, communication, and technical competencies have been previously verified as critical success factors for online learning in previous research, and while the Student Online Learning Readiness (SOLR) instrument can be used by educators or administrators in higher education, there are other learning characteristics of distance learners which may have an effect on their successful learning outcomes and level of satisfaction in online education. Further research on these other factors is necessary.

\section{Implications}

While online learning is becoming a common occurrence in higher education in the United States, it also has given rise to several problems, such as lower retention rates in online courses rather than face-to-face courses. As Tinto (1998) asserted, a low sense of belonging in an online course is one of the significant factors related to lower retention rates in online formats. For this reason, it is necessary for educators and/or administrators to try and instill a sense of belonging for their distance students and to consider how to support their students in order to enhance their own sense of belonging in each online course. The new instrument developed and tested in this study provides a solution for these students. As a theoretical framework, Tinto's (1975) Student Integration Model (SIM) emphasized the importance of social competencies with instructors and classmates on student retention. However, it is more difficult interacting socially with instructors and classmates in online learning environments than in face-to-face classroom settings (Ma \& Yuen, 2010). In addition, distance learners' retention rates are significantly lower than traditional students' retention rates (Ali \& Leeds, 2009; Angelina, Williams, \& Natvig, 2007; Holder, 2007; Lee \& Choi, 2011). Therefore, the levels of social competencies with instructors and classmates play a key role in online learning.

In addition, the results of this study have confirmed the four factor structure of the Student Online Learning Readiness (SOLR) instrument which consists of four categories (i.e. social competencies with the instructor, social competencies with classmates, communication competencies, and technical competencies). This study was looking at two factors of social integration in Tinto's SIM and has introduced the Student Online Learning Readiness (SOLR) conceptual model with the purpose of extending Tinto's social integration to an online learning environment. The significant influences of social 
competencies (Chen et al., 2010; Parker et al., 2006; Williams, 2003), communication competencies (Betermieux \& Heuel, 2009; Dabbagh, 2007; Dabbagh \& Bannan-Ritland, 2005; Volery \& Lord, 2000; Williams, 2003), and technical competencies (Osika \& Sharp, 2002; Selim, 2007; Watulak, 2012; Whale, 2006) have been verified by previous research. Therefore, it is now found to be possible to measure the levels of a learner's social, communication, and technical competencies through use of the Student Online Learning Readiness (SOLR) instrument before the learner takes an online course. Social, communication, and technical competencies are just three factors among other learner characteristics that have positive effects on academic achievement in online learning environments. While these three competencies are not enough to guarantee student success in online learning, we still need to pay more attention to these learner competencies as a starting point of supporting distance learners before they take an online course.

This study also provides two suggestions for practice. First, it provides an idea to consider what types of psychometric properties should be measured to better understand student social readiness in online learning. It is true technological issues such as computer skills, Internet connection, and Learning Management System (LMS) navigation ability have an impact because those are main components of the online learning environment. However, technological skills will not guarantee an improved learning experience alone. Although the online learning environment differs from the traditional face-to-face classroom learning environment, instructors and students still play a main role in the process of learning in an online course. For these reasons, educators and administrators in higher education need to pay more attention to distance learners' competencies in online learning (e.g. social competencies, communication competencies, and technical competencies).

Second, this study provides a suggestion regarding the kinds of supports needed for distance learners to succeed in online learning. To improve the lower retention rate in online learning, institutional supports such as freshmen orientation before taking an online course are significant (Ali \& Leeds 2009; Cho, 2012; Lee \& Choi, 2011). The Student Online Learning Readiness (SOLR) instrument developed and validated in this study could provide a guide on how to measure student competencies in online learning and what components should be included in their orientations or supports to enhance their student competencies in online learning.

\section{Suggestions for Practice}

If learners lack the competency levels necessary to be successful in online courses, they should be provided the opportunity to develop their competencies so as to avoid a more difficult situation involving non-content learning related challenges which could prevent them from succeeding in online learning. However, many educators in higher education are not aware how to measure their learners' social, communication, and technical competencies. Therefore, educators can use the Student Online Learning Readiness (SOLR) instrument to measure learners' competencies in online learning before they take an online course. In addition, it is necessary to provide an adequate social and academic support system in order to enhance students' senses of belonging in online learning - both for an increase in meaningful learning experiences and higher retention rates (Ali \& Leeds, 2009; Atchley, Wingenbach, \& Akers, 2012; Ludwig-Hardman \& Dunlap, 2003). However, existing student readiness instruments tend to ask about the learner's computer skills, technology accessibility, or initial thoughts regarding online learning that are not related to the social aspects of online learning. Therefore, educators also can use the Student Online Learning Readiness (SOLR) instrument as a more contemporary instrument to measure distance learners' readiness by combining social, communication, and technical competencies.

\section{Limitations}

There were four limitations with regard to this study. The first limitation related to the analysis method. Exploratory Factor Analysis (EFA) is an advantageous statistical method used to examine the 
construct validity and psychometric properties of an instrument. However, because EFA is not a sufficient tool to test the theoretical foundations of the instrument, a Confirmatory Factor Analysis (CFA) should be conducted to further the knowledge in this area. The second limitation of this study is an essential sampling bias. The samples in this study were collected from the online courses at a single university. This sampling process might threaten the ability to generalize the results of this study although various samples were included from different majors or programs. The third limitation is a response bias in questionnaire design. The online survey was distributed with two sections. The first section consisted of 10 items for social competencies and the second section included 12 items for communication and technical competencies. This type of survey formatting might cause acquiescence response bias because it is possible that participants tend to show the similar response patterns in a section. The last limitation in this study related to school setting because participants in this study were not enrolled in complete online programs but rather individual online course(s). Although the survey asked them to answer the questions as a current learner or potential learner in an online course, it is possible participants answered the questions based on experiences as both face-to-face and a distance learners. For this reason, it is possible different results might have been found if this study were conducted with students in a fully online program.

\section{Future Research}

For future research, it is recommended this study be repeated with students from multiple colleges or universities to overcome the statistical sampling bias. Another recommendation is to conduct a Confirmatory Factor Analysis (CFA) to test predictive validity of the Student Online Learning Readiness (SOLR) instrument since this study focused on Exploratory Factor Analysis (EFA) and reliability analysis to test the reliability and validity of the instrument. In addition, it is recommended further research be conducted to compare student readiness between students enrolled in a fully online program and those that are taking a single online course. This study did not consider the possible effect on the research results depending on the reason why students took the online courses. A final suggestion is to extend this study to other significant success factors in online learning (e.g. motivation, self-efficacy) in order to better measure student readiness in online learning more precisely and further refine the theoretical framework for the SOLR.

\section{References}

Ali, R., \& Leeds, E. (2009). The impact of classroom orientation in online student retention. Online Journal of Distance Learning Administration, 12(4). Retrieved from http://www.westga.edu/*distance/ojdla/winter124/ali124.html.

Allen, I. E., \& Seaman, J. (2013). Changing course: ten years of tracking online education in the United States. Babson Survey Research Group and Quahog Research Group, LLC. Retrieved from http://www.onlinelearningsurvey.com/reports/changingcourse.pdf

Allen, I. E., \& Seaman, J. (2014). Grade change: tracking online education in the United States. Babson Survey Research Group and Quahog Research Group, LLC. Retrieved from http://www.onlinelearningsurvey.com/reports/gradechange.pdf

Anderson, P. K. (2014). University education as relational: the challenge of online studies. Contemporary PNG Studies: DWU Research Journal, 19, 36-49. 
Angelina, L. M, Williams, F. K., \& Natvig, D. (2007) Strategies to engage online students and reduce attrition. Journal of educators online, 4(2). 3-14.

Atchley, T., Wingenbach, G., \& Akers, C. (2013). Comparison of course completion and student performance through online and traditional courses. The International Review of Research in Open and Distance Learning, 14(4). Retrieved from http://www.irrodl.org/index.php/irrodl/article/view/1461

Bakia, M., Shear, L., Toyama, Y., \& Lasseter, A. (2012). Understanding the implications of online learning for educational productivity. Washington, DC: U.S. Department of Education, Office of Educational Technology. Retrieved from http://www.sri.com/sites/default/files/publications/implications-online-learning.pdf

Battistich, V., Solomon, D., Watson, M., \& Schaps, E. (1997). Caring school communities. Educational Psychologist, 32, 137-151.

Ben-Jacob, M. (2011). Technology and critical inquiry: a necessary foundation for today's student. Proceedings of the World Conference on Educational Multimedia, Hypermedia and Telecommunications 2011 (pp. 3388-3391). Chesapeake, VA: AACE.

Bernard, R.M., Brauer, A., Abrami, P.C., \& Surkes, M. (2004). The development of a questionnaire for predicting online learning achievement. Distance Education, 25(1), 31-47.

Betermieux, S., \& Heuel, E. (2009). Design and use of a web based support tool for students' selfmanagement in university and distance university settings. Paper presented at the World Conference on Online learning in Corporate, Government, Healthcare, and Higher Education 2009, Chesapeake, VA.

Blunch, N. J. (2008). Introduction to structural equation modelling using SPSS and AMOS. Thousand Oaks, CA: Sage Publications Ltd.

Boomsma A. (1982). The robustness of LISREL against small sample sizes in factor analysis models. In H. Wold \& K. Jöreskog (Eds.), Systems under indirect observations (pp. 147-173). New York: Elsevier North-Holland.

Carey, J. M., (2011). Effective student outcomes: a comparison of online and face-to-face delivery modes. DEOSNEWS, 11(9). Retrieved from http://learningdesign.psu.edu/deos/deosnews11_9.pdf

Carr, S. (2000). As distance education comes of age, the challenge is keeping the students. The Chronicle of Higher Education, February 11, A39.

Cattell, R. B. (1966). The meaning and strategic use of factor analysis. In R. B. Cattell (Ed.), Handbook of multivariate experimental psychology (pp. 174-243). Chicago: Rand McNally.

Chen, X., Huang, X., Chang, L., Wang, L., \& Li, D. (2010). Aggression, social competence, and academic achievement in Chinese children: a 5-year longitudinal study. Development and Psychopathology, 22(Special Issue 03), 583-592. doi:10.1017/S0954579410000295.

Cho, M.-H. (2012). Online student orientation in higher education: a development study. Educational Technology Research and Development, 60(6), 1051-1069.

Cho, M.-H., \& Jonassen, D. (2009). Development of the human interaction dimension of the selfregulated learning questionnaire in asynchronous online learning environments. Educational Psychology, 29, 117-138. 
Cho, M.-H., Shen, D., \& Laffey, J. (2010). Relationships between self-regulation and social experiences in asynchronous online learning environments. Journal of Interactive Learning Research, 21, 297-316.

Comrey, A. L. \& Lee, H. B. (1992). A first course in factor analysis (2nd edition). Hillsdale, NJ: Erlbaum.

Dabbagh, N. (2007). The online learner: characteristics and pedagogical implications. Contemporary Issues in Technology and Teacher Education, 7(3), 217-226. Retrieved from http://www.citejournal.org/vol7/iss3/general/article1.cfm.

Dabbagh, N., \& Bannan-Ritland, B. (2005). Online learning: concepts, strategies, and application. Upper Saddle River, NJ: Prentice Hall.

Dray, B.J., \& Miszkiewicz, M. (2007). The intersection of learner characteristics and technology capabilities: implications for online learning. Paper presented at the 2007 AERA Annual Meeting, Chicago, IL.

Duck, J. M., \& Parente, D. H. (2014). How do we get to tomorrow? The path to online learning. Developments in Business Simulation and Experiential Learning, 35, 353-354.

Field, A. P. (2009). Discovering statistics using SPSS. London, England : SAGE.

Flook, L., Repetti, R. L., \& Ullman, J. B. (2005). Classroom social experiences as predictors of academic performance. Developmental Psychology, 41(2), 319-327.

Floyd, F. J., \& Widaman, K. F. (1995). Factor analysis in the development and refinement of clinical assessment instruments. Psychological Assessment, 7(3), 286-299.

Furrer, C., \& Skinner, E. (2003). Sense of relatedness as a factor in children's academic engagement and performance. Journal of Educational Psychology, 95(1), 148-162.

Goodenow, C. (1993). The psychological sense of school membership among adolescents: scale development and educational correlates. Psychology in the Schools, 30, 70-90.

Heo, M. (2011). Improving technology competency and disposition of beginning pre-service teachers with digital storytelling. Journal of Educational Multimedia and Hypermedia, 20(1), 61-81.

Herrera, L., \& Mendoza, N. (2011). Technological and pedagogical perceptions on b-learning from two opposite academic programs. Proceedings of the World Conference on Educational Multimedia, Hypermedia and Telecommunications 2011 (pp. 1078-1084). Chesapeake, VA: AACE.

Holder, B. (2007). An investigation of hope, academics, environment, and motivation as predictors of persistence in higher education online programs. Internet \& Higher Education, 10(4), 245-260. doi:10.1016/j.iheduc.2007.08.002.

Jun, J. (2005). Understanding E-dropout. International Journal on E-Learning, 4(2), 229-240.

Kaiser, H. F. (1960). The application of electronic computers to factor analysis. Educational and Psychological Measurement, 20, 141-151.

Kaiser, H.F. (1974) An index of factorial simplicity. Psychometrika, 39, 31-36.

Kass, R. A. \& Tinsley, H. E. A. (1979). Factor analysis. Journal of Leisure Research, 11, 120-138. 
Kerka, S. (1998). Competency-based education and training. Myths and realities. Retrieved from http://www.calpro-online.org/eric/textonly/docgen.asp?tbl=mr\&ID=65.

Kerr, M.S., Rynearson, K., \& Kerr, M.C. (2006). Student characteristics for online learning success. The Internet and Higher Education, 9(2), 91-105.

Kim, J. (2011). Developing an instrument to measure social presence in distance higher education. British Journal of Educational Technology, 42(5), 763-777. doi: 10.1111/j.1467-8535.2010.01107.x.

Lee, Y., \& Choi, J. (2011). A review of online course dropout research: implications for practice and future research. Educational Technology Research and Development, 59, 593-618.

Lee, Y., \& Choi, J. (2013). A structural equation model of predictors of online learning retention. The Internet and Higher Education, 16, 36-42.

Link, D. \& Scholtz, S. (2000). Educational technology and faculty role: what you don't know can hurt you. Nurse Educator, 25(6), 274-276.

Ludwig-Hardman, S., \& Dunlap, J. C. (2003). Learner support services for online students: scaffolding for success. International Review of Research in Open and Distance Learning, 4(1), 1-15.

Ma, W., \& Yuen, A. (2010). Understanding online knowledge sharing: an exploratory theoretical framework. Proceedings of Third International Conference of Hybrid Learning (pp 239-248). Beijing, China: ICHL.

Mattice, N. J., \& Dixon, P. S. (1999). Student preparedness for distance education (Research Report). Santa Clarita, CA: College of the Canyons.

McCubbin, I. (2003). An examination of criticisms made of Tinto's 1975 student integration model of attrition. Retrieved from http://www.psy.gla.ac.uk/ steve/localed/icubb.pdf.

McInnerney, J. M., \& Roberts, T. S. (2004). Online learning: social interaction and the creation of a sense of community. Educational Technology \& Society, 7(3), 73-81.

McMillan, J.H. (2007). Classroom assessment: principles and practice for effective standards-based instruction (4th ed.). Boston: Pearson.

McVay, M. (2001). How to be a successful distance education student: learning on the Internet. New York: Prentice Hall.

Moore, M., \& Kearsley, G. (2005). Distance education-a system view. Belmont, CA: Wadsworth Publishing Company.

Myllylä, M., \& Torp, H. (2010). Second Life in building social competence in teacher education. Proceedings of the Society for Information Technology \& Teacher Education International Conference 2010 (pp. 2795-2798). Chesapeake, VA: AACE.

Netemeyer, R. G., Bearden, W. O., \& Sharma, S. (2003). Scaling procedures: issues and applications. Sage Publications, London.

Osika, E. R., \& Sharp, D. P. (2002). Minimum technical competencies for distance learning students. Journal of Research on Technology in Education 34(3), 318-325. 
Osterman, K. F. (2000). Students' need for belonging in the school community. Review of Educational Research, 70, 323-367.

Parker, J. D. A., Hogan, M. J., Eastabrook, J. M., Oke, A., \& Wood, L. M. (2006). Emotional intelligence and student retention: predicting the successful transition from high school to university. Personality and Individual Differences, 41(7), 1329-1336.

Parnell, J.A., \& Carraher, S. (2002). The role of effective resource utilization in strategy's impact on performance. International Journal of Commerce and Management, 13(3), 1-34.

Reio, T. G., \& Crim, S. J. (2006). The emergence of social presence as an overlooked factor in asynchronous online learning. Paper presented at the Academy of Human Resource Development International Conference (AHRD), Columbus, $\mathrm{OH}$.

Poellhuber, B., Chomienne, M., \& Karsenti, T. (2008). The effect of peer collaboration and collaborative learning on self-efficacy and persistence in a learner-paced continuous intake model. Journal of Distance Education, 22(3), 41-62.

Saud, M. S., Buntat, Y., Minghat, A. D., \& Subari, K. (2010). Competency, importance and educational needs of online learning technology (OLT) competencies perceived as needed by technical and vocational teacher in malaysia. European Journal of Social Sciences, 14(4), 621-627.

Schreiber, J. A., Stage, F. K., King, J., Nora, A., \& Barlow, E. A. (2006). Reporting structural equation modeling and confirmatory factor analysis results: a review. The Journal of Educational Research, 99, 323-337.

Selim, H. M. (2007). Critical success factors for online learning acceptance: confirmatory factor models. Computers \& Education, 49, 396-413.

Shen, D., Cho, M., Tsai, C., \& Marra, R. (2013). Unpacking online learning experiences: online learning self-efficacy and learning satisfaction. Internet and Higher Education, 19, 10-17.

Smith, T. C. (2005). Fifty-one competencies for online instruction. The Journal of Educators Online, 2(2), $1-18$.

Soong, M. H. B., Chan, H. C., Chua, B. C., \& Loh, K. F. (2001). Critical success factors for on-line course resources. Computers \& Education, 36(2), 101-120.

Spector, J. M. (2001). Glossary of IBSTPI instructional design terms. In R. C. Richey, D. C. Fields, \& M. Foxon (Eds.), Instructional Design Competencies: The Standards. Syracuse (pp. 179-184). New York: ERIC Clearinghouse on Information \& Technology.

Tabachnick, B. G., \& Fidell, L. S. (2013). Using multivariate statistics, 6th ed. Boston: Pearson.

Thompson, B. (2004). Exploratory and confirmatory factor analysis: understanding concepts and applications. American Psychological Association, Washington DC.

Tinto, V. (1975). Dropout from higher education: a theoretical synthesis of recent research. Review of Educational Research, 45(1), 89-125.

Tinto, V. (1988). Stages of student departure: reflections on the longitudinal character of student leaving. Journal of Higher Education, 59(4), 438-455. 
Tinto, V. (1993). Leaving college: rethinking the causes and cures of student attrition (2nd ed.). Chicago: University of Chicago Press.

Tinto, V. (1998). Colleges as communities: taking research on student persistence seriously. The Review of Higher Education, 21(2), 167-177.

Tinto, V. (2000). Taking retention seriously: rethinking the first year of college. NACADA Journal, 19(2), 5-10.

Tinto, V. (2005). Reflections on student retention and persistence: moving to a theory of institutional action on behalf of student success. Studies in Learning, Evaluation, Innovation and Development, 2(3), 89-97.

Tinto. V. (2006). Taking student retention seriously. Keynote presentation and paper at Maricopa Community College District, 6 January. Retrieved from http://www.umesgolf.com/assets/0/232/3812/4104/4110/bd28b4ae-e1cc-4575-9b37535d2d2be5f1.pdf

Tinto. V. (2008). Access without support is not opportunity. Paper presented at the 36th Annual Institute for Chief Academic Officers, The Council of Independent Colleges, Seattle, Washington.

Volery, T., \& Lord, D. (2000). Critical success factors in online education. The International Journal of Educational Management, 14(5), 216-223.

Watulak, S. L. (2012). 'I'm not a computer person': negotiating participation in academic discourses. British Journal of Educational Technology, 43(1), 109-118.

Wetzel, A. P. (2011). Factor analysis methods and validity evidence: a systematic review of instrument development across the continuum of medical education. Unpublished doctoral dissertation: Virginia Commonwealth University.

Whale, D. (2006). Technology skills as a criterion in teacher evaluation. Journal of Technology and Teacher Education, 14(1), 61-74.

Williams, P. E. (2003). Roles and competencies of distance education programs in higher education institutions. The American Journal of Distance Education, 17(1), 45-57.

Wozney, L., Venkatesh, V., \& Abrami, P. (2006). Implementing computer technologies: teachers' perceptions and practices. Journal of Technology and Teacher Education, 14(1), 173-207.

Yu, T. (2014). Student readiness for online learning: the role of social, emotional and technical competencies. In R. L. Patrick, C. S. York, \& J. C. Richardson (Eds.), Online Learning: Common Misconceptions, Benefits and Challenges (pp. 17-31). New York: Nova Science Publishers, Inc.

Zawacki-Richter, O. (2004). The growing importance of support for learners and faculty in online distance education. In J. E. Brindley, C. Walti, \& O. Zawacki-Richter (Eds.), Learner Support in Open, Distance and Online Learning Environment (pp. 51-62). Bibliotheks- und Informationssystem der Universität Oldenburg. 